Article

\title{
DFT Study on the Mechanism of Iron-Catalyzed Diazocarbonylation
}

\author{
Tímea R. Kégl ${ }^{1, t, \ddagger}$, László Kollár ${ }^{1,2, t, \ddagger(\mathbb{D})}$ and Tamás Kégl ${ }^{1, *, t, \ddagger(D)}$ \\ 1 Department of Inorganic Chemistry and MTA-PTE Research Group for Selective Chemical Syntheses, \\ University of Pécs, H-7624 Pécs, Hungary; trkegl@gamma.ttk.pte.hu (T.R.K.); \\ kollar@gamma.ttk.pte.hu (L.K.) \\ 2 Department of Inorganic Chemistry and János Szentágothai Research Centre, University of Pécs, \\ H-7624 Pécs, Hungary \\ * Correspondence: tkegl@gamma.ttk.pte.hu; Tel.: +36-72-501-500 \\ + Current address: Ifjúság útja 6., H-7624 Pécs, Hungary. \\ $\ddagger$ These authors contributed equally to this work.
}

Academic Editor: Andreas A. Danopoulos

Received: 14 November 2020; Accepted: 07 December 2020; Published: 11 December 2020

\begin{abstract}
The mechanism of the carbonylation of diazomethane in the presence of iron-carbonyl-phosphine catalysts has been investigated by means of DFT calculations at the M06/def-TZVP/ / B97D3/def2-TZVP level of theory, in combination with the SMD solvation method. The reaction rate is determined by the formation of the coordinatively unsaturated doublet-state $\mathrm{Fe}(\mathrm{CO})_{3}(\mathrm{P})$ precursor followed by the diazoalkane coordination and the $\mathrm{N}_{2}$ extrusion. The free energy of activation is predicted to be 18.5 and $28.2 \mathrm{kcal} / \mathrm{mol}$ for the $\mathrm{PF}_{3}$ and $\mathrm{PPh}_{3}$ containing systems, respectively. Thus, in the presence of less basic P-donor ligands with stronger $\pi$-acceptor properties, a significant increase in the reaction rate can be expected. According to energy decomposition analysis combined with natural orbitals of chemical valence (EDA-NOCV) calculations, diazomethane in the $\mathrm{Fe}(\mathrm{CO})_{3}$ (phosphine) $\left(\eta^{1}-\mathrm{CH}_{2} \mathrm{~N}_{2}\right)$ adduct reveals a $\pi$-donor- $\pi$-acceptor type of coordination.
\end{abstract}

Keywords: iron-carbonyls; diazocarbonylation; DFT

\section{Introduction}

Ketenes are important and versatile intermediates in synthetic organic chemistry [1-5]. They can form various carboxylic acid derivatives, such as esters, anhydrides, and amides reacting readily with alcohols, carboxylic acids, or primary amines, respectively [6]. A notable category of ketene reactions is their facile [2+2] cycloaddition with alkenes, dienes, or imines [7,8]. The reactive ethoxycarbonyl ketene can be trapped in situ by various scavengers such as alcohols, amines, and imines affording the corresponding malonic acid derivatives or $\beta$-lactams, respectively [9]. Moreover, in the co-catalyzed domino reaction of ethyl diazoacetate (EDA) with $\mathrm{CO}$, in the presence of ferrocenylimines, the synthesis of unsaturated malonic acid derivatives has also been reported [10,11].

One straightforward way leading to ketenes is the metal-mediated substitution of the diazo group in diazoalkanes, as depicted in Scheme 1. The first metal-mediated example for the carbonylation of diazoalkanes was reported by Rüchard and Schrauzer in 1960 [12]. Nickel tetracarbonyl served as both catalyst precursor and CO surrogate for converting diazomethane, diphenyldiazomethane, and ethyl diazoacetate to the corresponding ketenes. In the following decades, no other similar results were published, despite the potential synthetic importance of the diazocarbonylation reaction. 


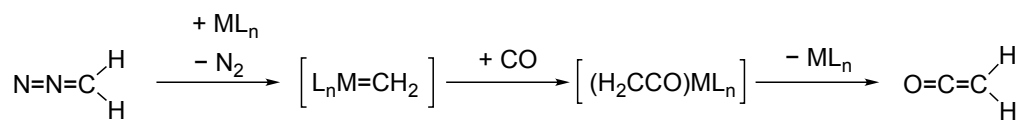

Scheme 1. Catalytic transformation of diazomethane in the presence of transition metal complexes and carbon monoxide.

A crucial step in the reaction is the formation of the ketene complex from the carbenoid that is afforded after the $\mathrm{N}_{2}$ extrusion. Grotjahn and co-workers studied the interconversion of diphosphine-substituted iridium carbonyl-carbene complexes by intramolecular $\mathrm{C}=\mathrm{C}$ bond cleavage/formation $[13,14]$. The equilibrium of the reversible step was predicted to be on the side of the carbonyl-carbene system, whereas for the analogous rhodium-containing systems the equilibrium was found to be on the ketene side.

The carbonylation of ethyl diazoacetate and trimethylsilyl diazomethane was thoroughly investigated in the presence of cobalt catalysts in $[15,16]$. For $\mathrm{Co}_{2}(\mathrm{CO})_{8}$, as a catalyst precursor, the reaction leading to diethyl malonate was found to occur in two different cycles. In the first one, the coordinatively unsaturated $\mathrm{Co}_{2}(\mathrm{CO})_{7}$ serves as the active catalyst, which forms the bridging carbonyl-carbene complex $\mathrm{Co}_{2}(\mathrm{CO})_{7}(\mathrm{CHCOOEt})$ after its reaction with EDA $[17,18]$. The catalytic cycle can go on with an intramolecular ketene formation and eventually the release of ketene, or with the dissociation of a terminal $\mathrm{CO}$ ligand giving rise to the unsaturated $\mathrm{Co}_{2}(\mathrm{CO})_{6}(\mathrm{CHCOOEt})$, which is also able to react with diazoalkanes, opening the second catalytic cycle [19]. In this pathway, a stable $\mathrm{Co}_{2}(\mathrm{CO})_{6}(\mathrm{CHCOOEt})_{2}$ dicarbene intermediate is formed, which can also couple one terminal carbonyl ligand affording complexes with ethoxycarbonylketene ligands. After dissociation, the ketene reacts with the trapping agent ethanol to form diethyl malonate as the final product [20].

Triphenylphosphine-substituted cobalt carbonyl complexes were found to be even more active precatalysts in the carbonylation of EDA. With two equivalents of $\mathrm{PPh}_{3}$, the presence of the ion pair $\left[\mathrm{Co}(\mathrm{CO})_{3}\left(\mathrm{PPh}_{3}\right)_{2}\right]\left[\mathrm{Co}(\mathrm{CO})_{4}\right]$ could be observed, which was assumed to interconvert to the corresponding radical pair under catalytic conditions [21].

The palladium-catalyzed diazocarbonylation, the subsequent domino reaction leading to $\beta$-lactams, and their mechanisms were investigated by Wang and co-workers [22]. For the computational studies, $\mathrm{Pd}-\mathrm{CO}$-ethylene complexes were postulated as model catalysts. It was suggested that the isomerization of the $\mathrm{C}=\mathrm{N}$ bond of the initially formed zwitterionic intermediate took place, which would give an explanation for the predominant formation of trans- $\beta$-lactams.

The mechanism of diazo activation and carbonylation was investigated in the presence of homoleptic and phosphine substituted nickel carbonyl catalysts in [23]. Substitution of CO by $\mathrm{PH}_{3}$ resulted in a decrease of the activation barrier, which was attributed to the combined catalyst formation $/ \mathrm{N}_{2}$ extrusion step. In contrast to the cobalt-containing systems, the mostly exergonic step was the carbene-carbonyl coupling instead of the formation of the carbenoid.

The goal of this work is to unravel the mechanism of diazomethane carbonylation in the presence of iron-carbonyl-phosphine complexes. The secondary purpose of this paper is to interpret the electronic structure of reaction intermediates and classify their donor-acceptor character using energy decomposition analysis combined with the natural orbitals of chemical valence (EDA-NOCV) as well as the natural bond orbital (NBO) methodology.

\section{Results and Discussion}

One of the straightforward synthetic routes leading to ketene is the carbonylation of diazoalkanes; that is, the replacement of the $\mathrm{N}_{2}$ moiety by carbon monoxide. The resulting carbenoid then transfers to the corresponding ketene complex via intramolecular carbene-carbonyl coupling. In all cases, the first step of the metal-mediated reaction is the coordination of diazoalkane to the metal. 


\subsection{Reaction of Diazomethane with Phosphine Substituted Iron Carbonyls}

The precursor for the catalytic reaction is the trigonal bipyramidal trans- $\left[\mathrm{Fe}(\mathrm{CO})_{3}(\mathrm{~L})_{2}\right]$ complex, which releases one of its ligands, thereby enabling the coordination of diazoalkane on the vacant site. Complex $1 F$ has a $D_{3 h}$ symmetry, which is reduced to $C_{3}$ in $\mathbf{1 P}$ because of the lack of symmetry planes. As expected, the strong acceptor property of the $\mathrm{PF}_{3}$ ligand results in a shorter $\mathrm{Fe}-\mathrm{P}, \mathrm{C}=\mathrm{O}$, and an elongated $\mathrm{Fe}-\mathrm{C}$ bond in $\mathbf{1 F}$, as compared to those in the complex $\mathbf{1 P}$ with $\mathrm{PPh}_{3}$. Since the dissociation of the carbonyl ligands is significantly more endergonic than that of the phosphines, only the formation of the unsaturated $\mathrm{Fe}(\mathrm{CO})_{3}(\mathrm{~L})$ complexes was examined. By the removal of one phosphine ligand, the resulting coordinatively unsaturated complexes $\mathbf{2 F}$ and $\mathbf{2} \mathbf{P}$ keep the symmetry of their "parent" complexes. In addition to these singlet state species, triplet structures were found, and they proved to be more stable in terms of free energy than their singlet state counterparts. The free energy difference is $13.2 \mathrm{kcal} / \mathrm{mol}$ between $\mathbf{2 F t}$ and $\mathbf{2 F}$, while $\mathbf{2} \mathbf{P t}$ is more stable than $\mathbf{2} \mathbf{P}$ by $11.8 \mathrm{kcal} / \mathrm{mol}$. The stability difference for these $\mathrm{Fe}(\mathrm{CO})_{3}(\mathrm{~L})$ types of complexes shows some similarity with that obtained for the unsaturated iron tetracarbonyl, where ${ }^{3}\left[\mathrm{Fe}(\mathrm{CO})_{4}\right]$ proved to be more stable by ca. $8 \mathrm{kcal} / \mathrm{mol}$ than the singlet state tetracarbonyl, according to Harvey and Aschi [24]. In the triplet structures, the Fe-P distances are slightly more elongated than those in the singlet structures. Instead of a threefold axis, only one symmetry plane remains in $2 \mathbf{F t}\left(\mathrm{C}_{S}\right.$ symmetry), as one of the $\mathrm{OC}-\mathrm{Fe}-\mathrm{CO}$ angles is increased to $148.7^{\circ}$. The symmetry is $\mathrm{C}_{1}$ for $2 \mathbf{P t}$, with a $\mathrm{OC}-\mathrm{Fe}-\mathrm{CO}$ angle of $148.1^{\circ}$. The structures of the initial phosphine substituted carbonyl complexes are depicted in Figure 1.
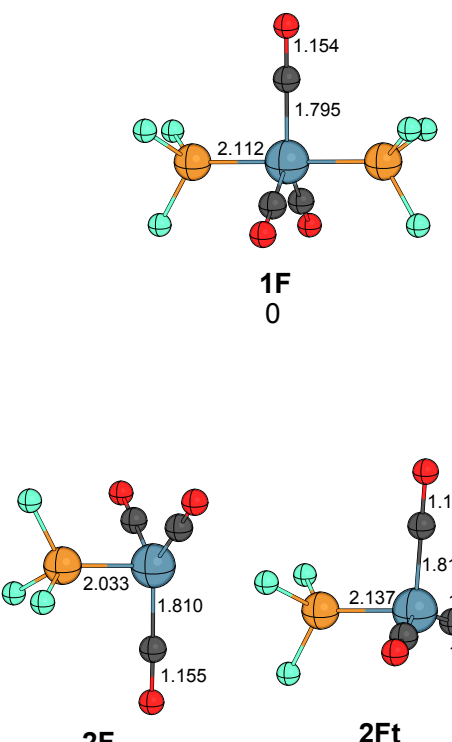

26.3

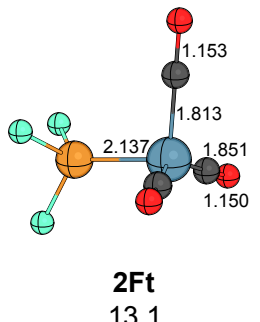

13.1
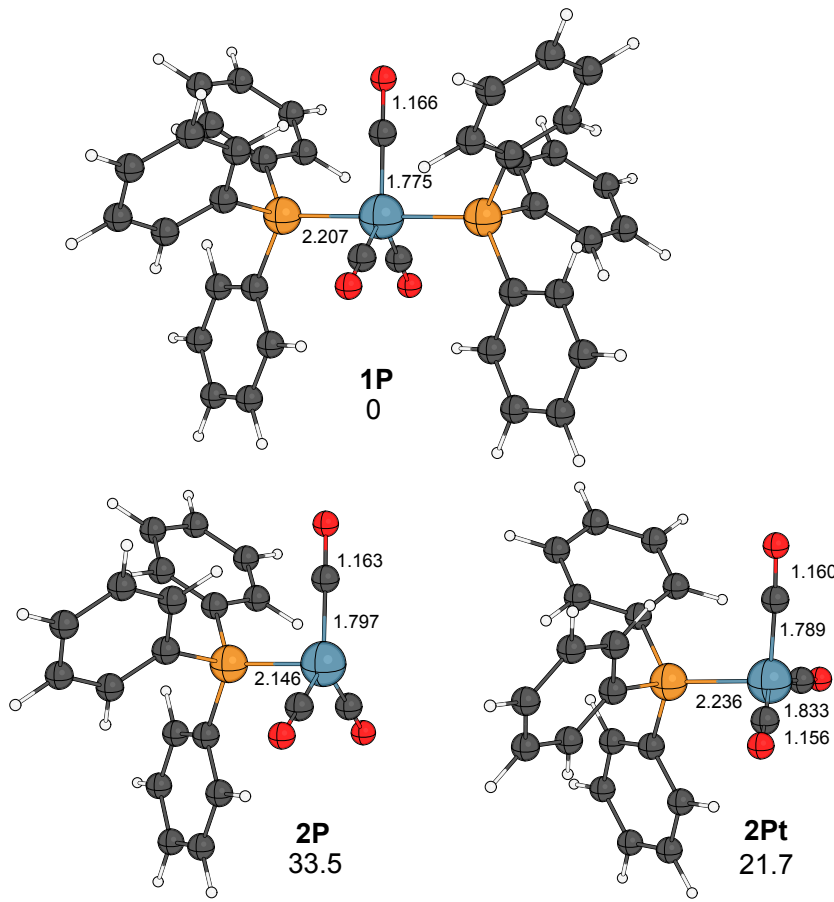

Figure 1. Computed structures of coordinatively saturated $\mathrm{Fe}(\mathrm{CO})_{3}(\mathrm{P})_{2}$ and unsaturated $\mathrm{Fe}(\mathrm{CO})_{3}(\mathrm{P})$ types of complexes. Gibbs free energy values are given in $\mathrm{kcal} / \mathrm{mol}$ and bond lengths are in $\AA$. The free energy values are relative to $\mathbf{1 F}$ (for the phosphorus-trifluoride-containing complexes) and $\mathbf{1 P}$ (for the triphenylphosphine-containing complexes).

Thus, in both cases, the triplet structures are preferred for the unsaturated $\mathrm{Fe}(\mathrm{CO})_{3}(\mathrm{~L})$ complexes, meaning that the dissociation of one phosphine ligand is expected to take place via a spin change. In Figure 2, the nearest approximation to the adiabatic transition state (that is, the minimum energy crossing point) is depicted for the phosphorus-trifluoride-containing system. On the triplet potential energy surface, we found no real stable diphosphine tricarbonyl complex, as in the local minimum of the saturated species, the iron-phosphorus bond distance exceeds $3 \AA$ (see Figure S1 
in the Supplementary Material). The spin state change takes place at a Fe-P distance of $3.23 \AA$. Another spin state change is expected to take place during the coordination of diazomethane.

To check the dependence of the spin state upon the functional, the free energy difference between the triplet and singlet states of complexes $\mathrm{Fe}(\mathrm{CO})_{3}(\mathrm{P})$ has been computed as well, employing the B3LYP and the TPSS functionals. It is known that in some cases nonhybrid functionals prefer the low-spin state, whereas B3LYP overstabilizes the triplet state [25]. Here, the free energy difference between $2 \mathbf{F}$ and $2 \mathbf{F t}$ was 6.5 and $14.9 \mathrm{kcal} / \mathrm{mol}$ for TPSS and B3LYP, respectively, in favor of the triplet structure. For the analogous complexes with triphenylphosphine, $\mathbf{2} \mathbf{P t}$ was more stable than $\mathbf{2 P}$ by 5.2 and $19.0 \mathrm{kcal} / \mathrm{mol}$ for TPSS and B3LYP, respectively, in terms of free energy. These results support the observation found at the M06/ / B97D3 level (that is, M06 energies on B97D3 geometries) that the catalytically active species is the triplet $\mathrm{Fe}(\mathrm{CO})_{3}(\mathrm{P})$ for both $\mathrm{P}$-donor ligands.

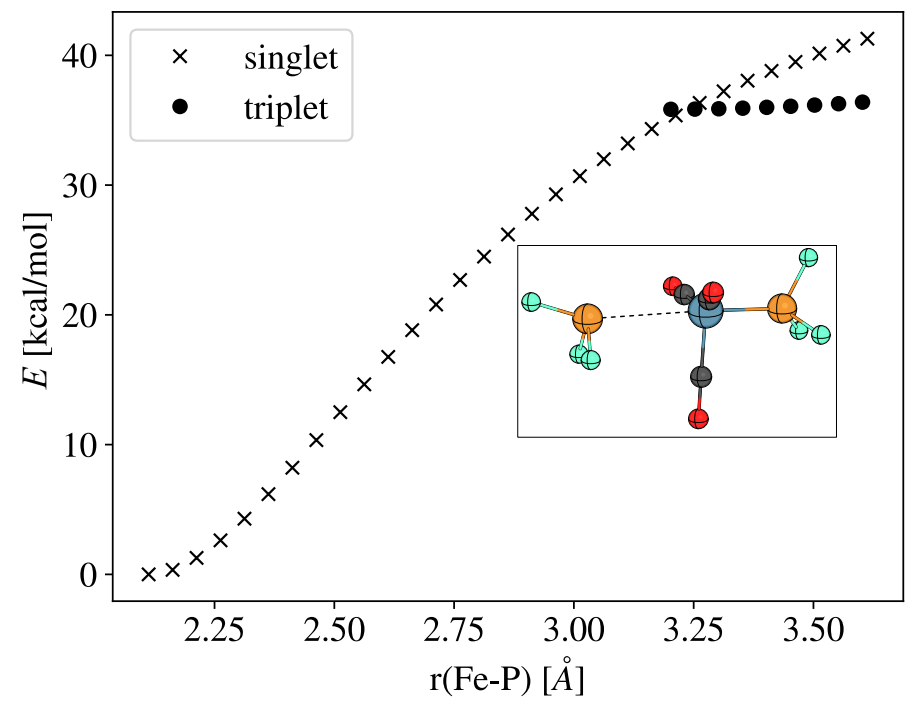

Figure 2. Energies of the partially optimized singlet and triplet $\mathrm{Fe}(\mathrm{CO})_{3}\left(\mathrm{PF}_{3}\right)_{2}$ relative to the overall singlet minimum, at various Fe-P distances. The computed structure in the inlet represents the minimum energy crossing point (MECP).

For metal-diazoalkane complexes, various coordination types are known in the literature. The most common ones are depicted in Scheme 2. The possibilities I. to V. were thoroughly checked for both phosphine ligand types. No $\eta^{2}$ coordination to the $\mathrm{Fe}(\mathrm{CO})_{3}\left(\mathrm{PR}_{3}\right)$ moiety was found; that is, the diazo coordination is predicted to proceed via $\eta^{1}$ diazo complexes. Scheme 3 illustrates the $\eta^{1}-\mathrm{N}$ diazo species, as well as the $\eta^{1}-\mathrm{C}$ complexes, where diazomethane can take either the axial or the equatorial position.<smiles>[M]C([R])[N+]=[N-]</smiles>

I.

$\eta^{1}-\mathrm{C}$<smiles>[M]N=[N+][C-]([R])[2H]</smiles>

II. $\eta^{1}-\mathrm{N}$<smiles>[R][C+]([O-])N1N=[N+]1</smiles>

III.

$\eta^{2}-(N, N)$<smiles></smiles>

IV.<smiles>[R][C@H]1[M]N=N1</smiles>

V.

$\eta^{2}-(\mathrm{N}, \mathrm{C})$

Scheme 2. Most common coordination modes for diazoalkanes bound to a single transition metal center. 

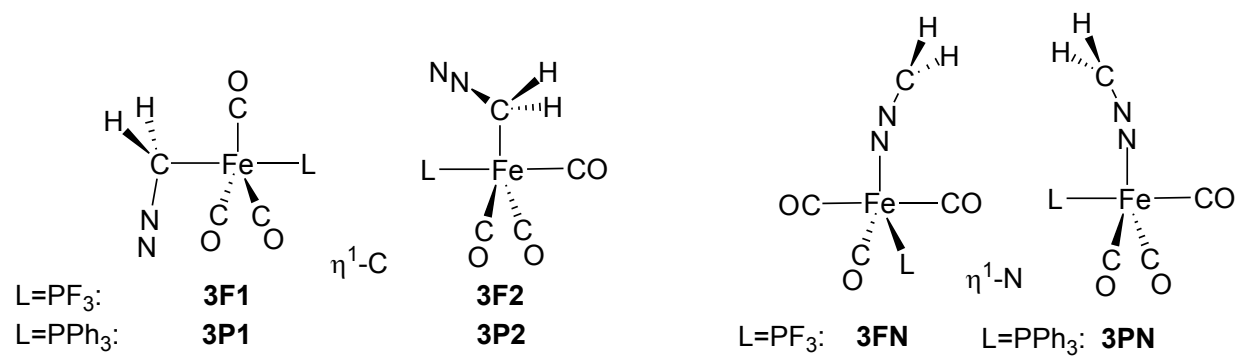

Scheme 3. Schematic representation of $\mathrm{Fe}(\mathrm{CO})_{3}(\mathrm{~L})$ (diazomethane) complexes with $\eta^{1}-\mathrm{C}$ and $\eta^{1}-\mathrm{N}$ coordination.

Probably because of steric reasons, only one example each was found for the $\eta^{1}-\mathrm{N}$ diazo adducts; the $\mathrm{PF}_{3}$ ligand is equatorial in 3FN, whereas $\mathrm{PPh}_{3}$ occupies the axial position in 3PN. For the $\eta^{1}-\mathrm{C}$ species, diazomethane can adopt both axial (3F1 and 3P1) and equatorial (3F2 and 3P2) positions; the axial complexes (with the P-donor ligand in trans position) are more stable for both $\mathrm{PF}_{3}$ and $\mathrm{PPh}_{3}$ with a free energy difference of 2.6 and $1.2 \mathrm{kcal} / \mathrm{mol}$, respectively. Complex 3FN is less stable than 3F1 by $1.3 \mathrm{kcal} / \mathrm{mol}$, however, $3 \mathbf{P N}$ is the most stable adduct in the presence of triphenylphosphine as it is more stable by $2.9 \mathrm{kcal} / \mathrm{mol}$ in comparison to $3 \mathbf{P 1}$. The computed structures of the diazo adducts are depicted in Figure 3.
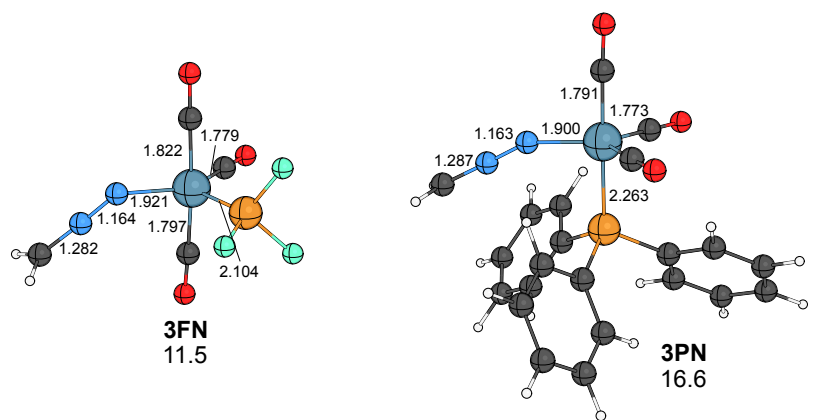
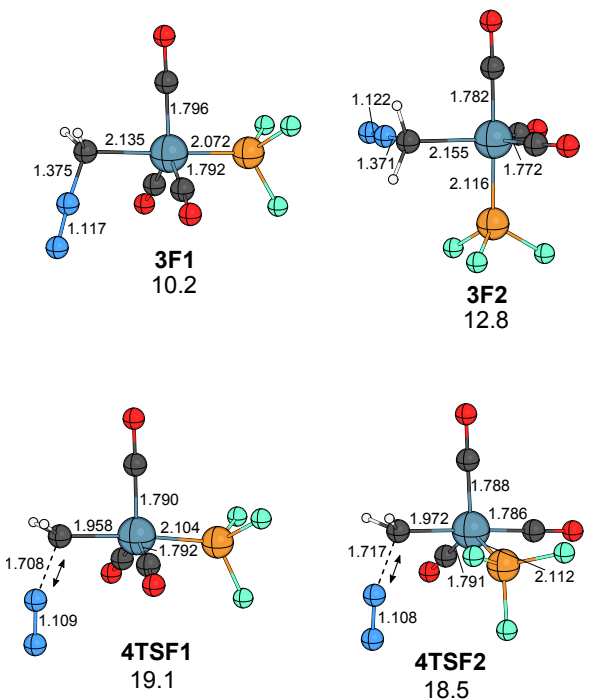
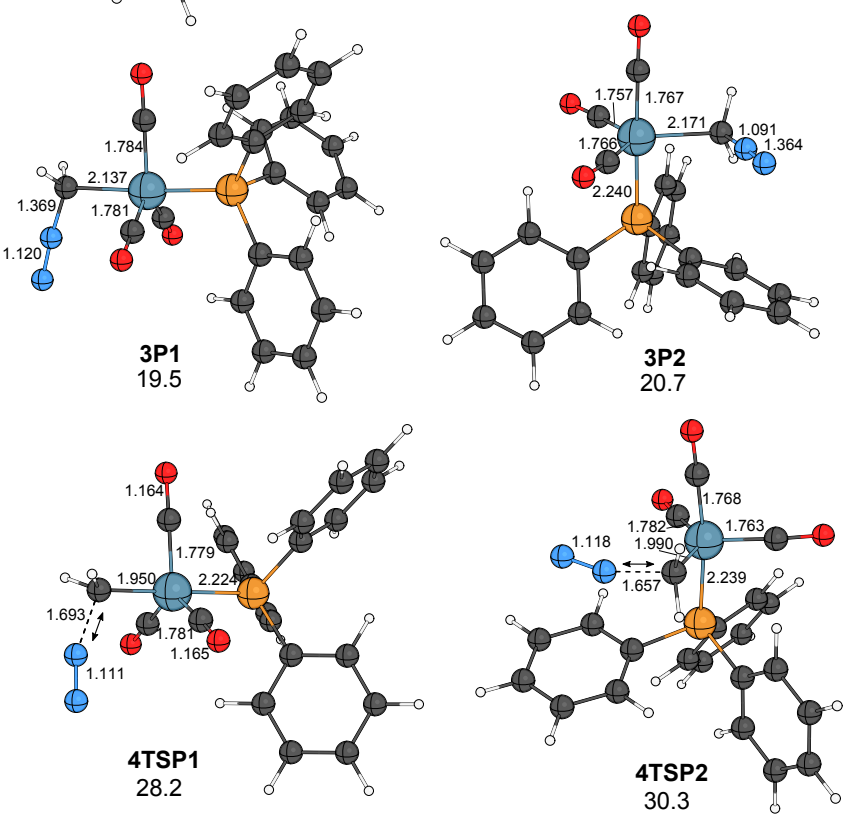

Figure 3. Computed minimum structures associated with the diazo coordination and activation steps, as well as transition states for the dinitrogen extrusion step. Bond distances are in $\AA$ and Gibbs free energy values are given in $\mathrm{kcal} / \mathrm{mol}$. Free energies are relative to $\mathbf{1 F}$ and $\mathbf{1 P}$.

The dominant interaction between the metal and diazomethane is remarkably different for the two $\eta^{1}$ coordination types of diazomethane, as it is unraveled by energy decomposition analyses 
within the framework of the natural orbitals of chemical valence method (EDA-NOCV) [26-29] and depicted in Figure 4. For the $\eta^{1}-\mathrm{N}$ case, the leading interaction is the back-donation to the diazo moiety with involvement of $d$ orbitals of iron extended with the lone pair of phosphorus. The main orbital interaction of complex 3F1, however, stems from the $\pi_{\mathrm{CN}}$ orbital; that is, even though the coordination type is $\eta^{1}$, the interaction is $\pi$-donor in character, whereas the acceptor NOCV is a combination of an empty $s d$ hybrid on $\mathrm{Fe}$, and the mixture of $\sigma_{\mathrm{PF}}^{*}$ and $\pi_{\mathrm{CO}}^{*}$ orbitals. It is interesting to note that the leading orbital interaction in $3 \mathbf{F 1}$ is twice as strong $(-40.5 \mathrm{kcal} / \mathrm{mol})$ as that in $3 \mathrm{FN}(-21.9 \mathrm{kcal} / \mathrm{mol})$.
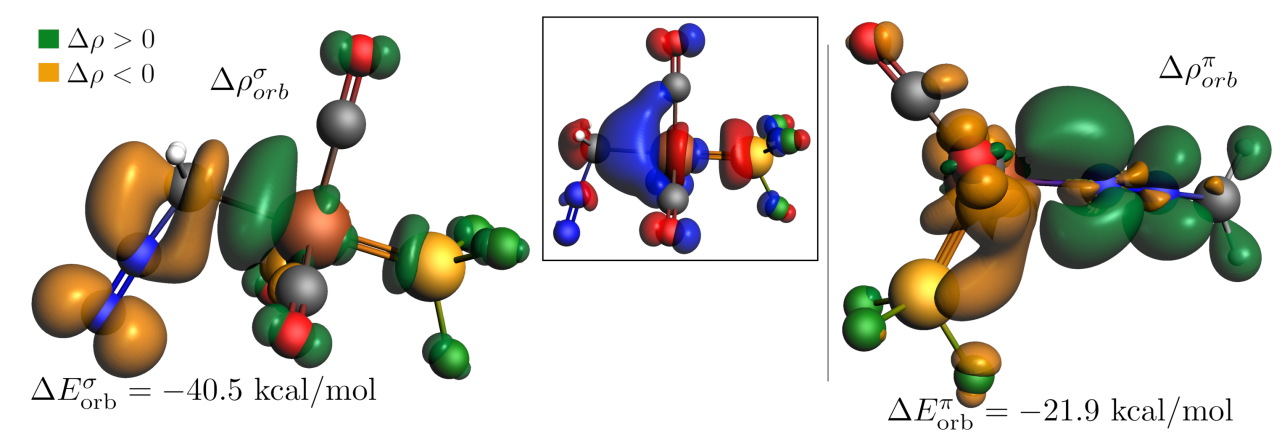

Figure 4. Natural orbitals of chemical valence (NOCV) deformation densities associated with the dominant interaction of the diazomethane complexes 3F1 (left) and 3FN (right). The inlet shows the acceptor NOCV orbital of 3F1 with the eigenvalue of 0.698 .

The adducts with diazoalkane undergo $\mathrm{N}_{2}$ extrusion resulting in metal carbenoids. The transition states (4TSF1, 4TSP1, 4TSF2, and 4TSP2) describing this process are originated from the respective $\eta^{1}-\mathrm{C}$ complexes. For the $\mathrm{PF}_{3}$-containing species, the equatorial pathway is slightly preferred (by $0.6 \mathrm{kcal} / \mathrm{mol}$ in terms of free energy), even though the corresponding diazo adduct is less stable than the axial one. On the other hand, the activation free energy difference is larger in the presence of $\mathrm{PPh}_{3}$, and the axial pathway is preferred by $2.1 \mathrm{kcal} / \mathrm{mol}$. For the $\eta^{1}-\mathrm{N}$ diazo complexes, it is also possible, in principle, to cleave the $\mathrm{C}-\mathrm{N}$ bond with the attack of an unsaturated complex on the diazo methylene group, as was described by Milstein and co-workers for Rh-diazo species [30]. A similar pathway was reported for the ketene formation from $\cdot \mathrm{Cr}(\mathrm{Cp})(\mathrm{CO})_{2}\left(\mathrm{NNCH}_{2}\right)$ with the addition to the . $\mathrm{Cr}(\mathrm{Cp})(\mathrm{CO})_{3}$ radical [31]. This pathway was checked only for $\mathrm{PF}_{3}$ with a transition state describing the reaction of $\mathbf{3 F N}$ with $\mathbf{2 F t}$ (see Figure S2 in the Supplementary Material), and the activation free energy was found to be $20.3 \mathrm{kcal} / \mathrm{mol}$; that is, this route is predicted to be the least favored compared to those involving the $\eta^{1}-\mathrm{C}$ complexes. On the triplet potential energy hypersurface (PES), the addition of diazomethane to the unsaturated phosphine-carbonyl complexes was examined as well. The relative free energies of the adducts exceeded those of the singlet state transition states by 5.9 and $3.2 \mathrm{kcal} / \mathrm{mol}$ for $\mathrm{PF}_{3}$ and $\mathrm{PPh}_{3}$, respectively, therefore we did not follow the triplet pathways of the $\mathrm{N}_{2}$ extrusion.

\subsection{Formation of Ketene Complexes}

The $\mathrm{N}_{2}$ extrusion is exergonic in all cases, resulting in the carbenoids 5F1 and 5P1 for the axial pathway and 5F2 and 5P2 for the equatorial pathway via transition states 4TSF1, 4TSP1, 4TSF2, and 4TSP2, respectively (Figure 3). Complex 5F1 is somewhat more stable thermodynamically than $\mathbf{5 F 2}$, however, there is no significant difference in stability for the triphenylphosphine-containing species. From the interaction of the methylene group with an adjacent $\mathrm{CO}$, coordinatively unsaturated ketene complexes are formed. The coupling follows the route through the 6TSF1 and 6TSP1 transition states for the axial, and 6TSF2 and 6TSP2 transition states for the equatorial reaction channels. On the axial pathway, complexes 7F1 and 7P1 have the P-donor ligand off the plane spanned by the ketene and carbonyl ligands. Ligands $\mathrm{PF}_{3}$ and $\mathrm{PPh}_{3}$, on the other hand, are in-plane in complexes 7F2 and 7P2. Species 7F1 and 7F2 are close to each other in terms of free energy, whereas 7P1 is notably less stable than 7P2 (Figure 5). 

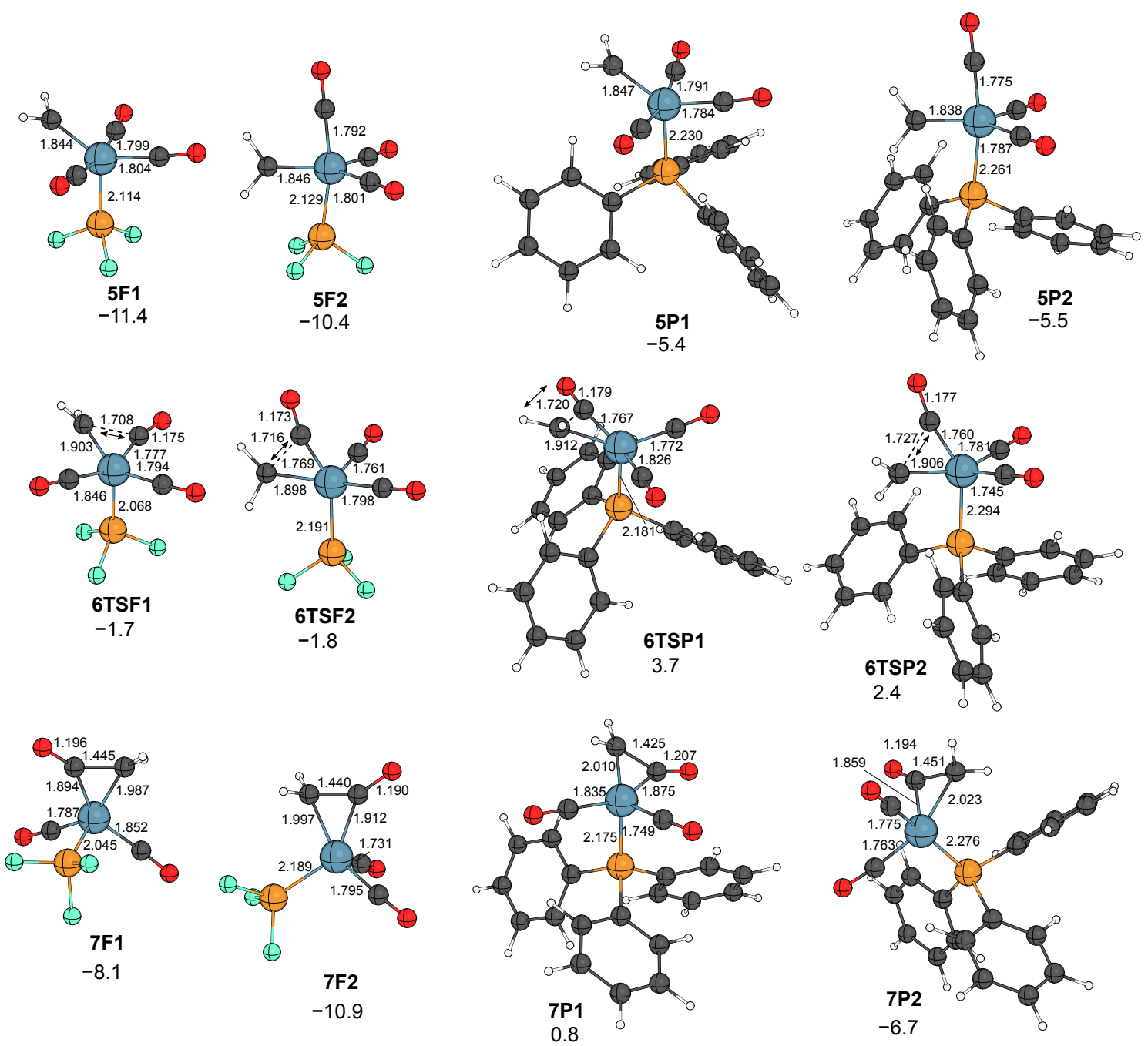

Figure 5. Computed minimum structures and the transition states describing the carbene-carbonyl coupling for the $\mathrm{PF}_{3}$ and $\mathrm{PPh}_{3}$ pathways for the $\mathrm{CO}$ uptake step leading to coordinatively saturated ketene complexes. Bond distances are in $\AA$, Gibbs free energy values are given in $\mathrm{kcal} / \mathrm{mol}$, and they are relative to $\mathbf{1 F}$ and $\mathbf{1 P}$.

The coordinatively unsaturated ketene complexes are prone to taking up one $\mathrm{CO}$ from the external carbon monoxide atmosphere. For the phosphorus-trifluoride-containing complexes, the $\mathrm{CO}$ coordination is barrierless, similar to the ketene complex with $\mathrm{PPh}_{3}$ on the equatorial pathway (7P2). For the axial pathway, however, the CO coordination proceeds via a transition state (8TSP1) with a free energy barrier of $6.6 \mathrm{kcal} / \mathrm{mol}$. The formation of the saturated complexes 9F1, 9F2, 9P1, and 9P2 is highly exergonic in all cases. In the presence of $\mathrm{PF}_{3}$, species $\mathbf{9 F} 2$ is more stable, where the P-donor ligand is in the Fe-ketene plane (Figure 6).

By inspection, there is no apparent difference in the charge distribution around the bound ketene in 7F2 and 9F2 (Figure 7). In accordance, however, with the larger Fe-C distances in 9F2, the delocalization indices for the iron-carbon interactions are smaller, as compared to those in the unsaturated 7F2. Consequently, the $\mathrm{C}-\mathrm{C}$ delocalization index is larger in $\mathbf{9 F}$, indicating a stronger carbon-carbon interaction. On the other hand, the $\mathrm{C}-\mathrm{C}$ bond ellipticity is smaller in the saturated complex, which implies a somewhat less pronounced double-bond character. It is interesting to note that in both cases the iron-carbon bond ellipticity is fairly high for the $\mathrm{Fe}--\mathrm{C}_{\text {carbonyl }}$ interaction (higher than that for the $\mathrm{C}--\mathrm{C}$ bond) and extremely high (1.350 for the unsaturated and 1.786 for the saturated complex) for the interaction between the iron center and the terminal carbon. 


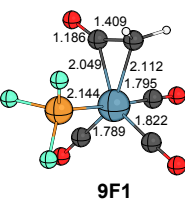

$-34.9$
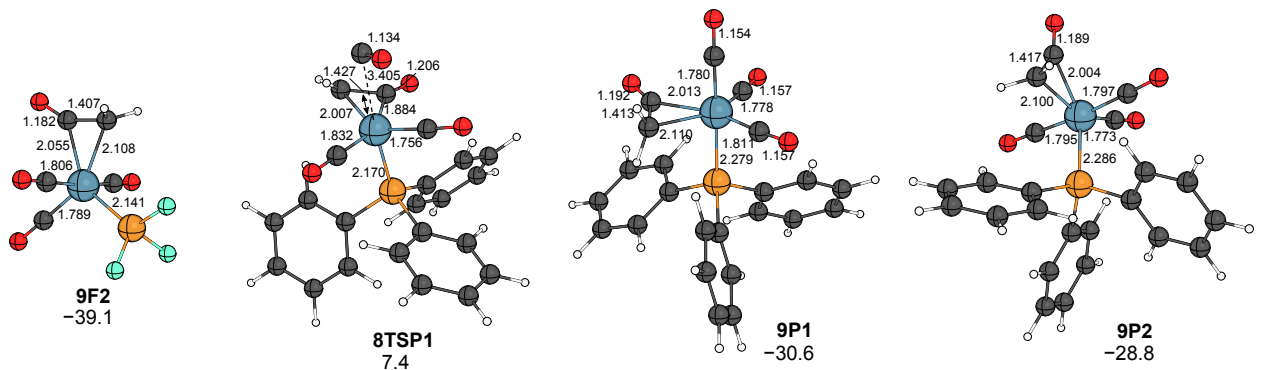

Figure 6. Computed minimum structures of the coordinatively saturated ketene complexes and transition states associated with the $\mathrm{CO}$ uptake in the presence of triphenylphosphine. Bond distances are in $\AA$, Gibbs free energy values are given in $\mathrm{kcal} / \mathrm{mol}$, and they are relative to $\mathbf{1 F}$ and $\mathbf{1 P}$.
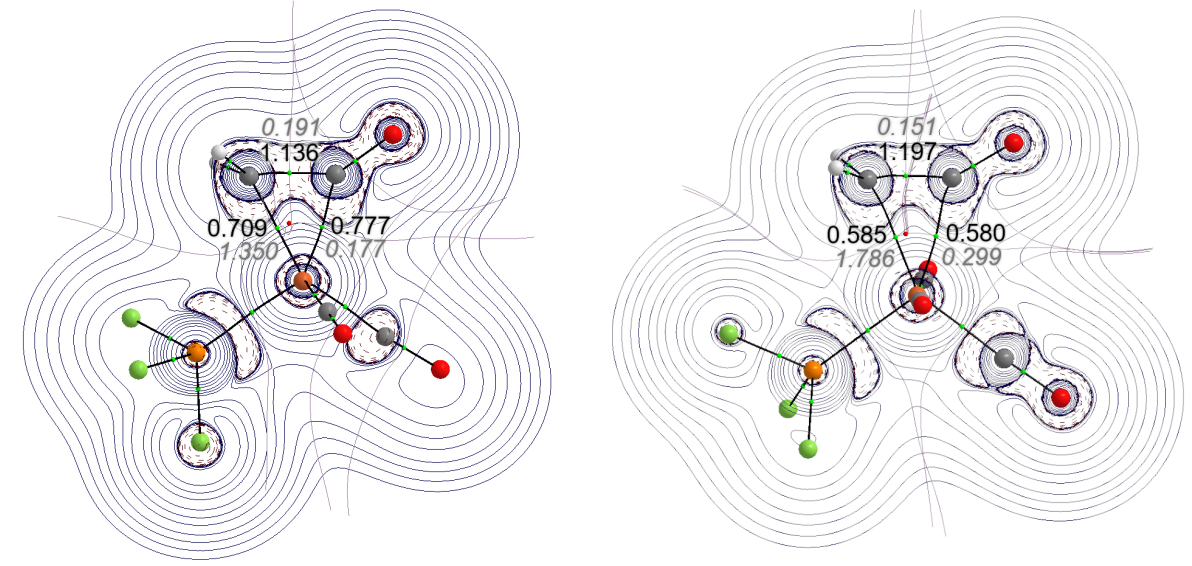

Figure 7. Contour-line diagrams of the Laplacian distribution $\left(\nabla^{2} \rho(\mathbf{r})\right)$ of the unsaturated (7F2, left) and saturated (9F2, right) ketene complexes with $\mathrm{PF}_{3}$ ligand.

Visualizing the charge flow within the saturated ketene complex 9F2, the most appealing feature to note is that the prevailing charge transfers are not separated between the metal-containing and the ketene fragments, but a significant part takes place within the ketene fragment (Figure 8). The main deformation density component $\left(\Delta \rho_{\text {orb }}^{1}\right)$ is associated with an orbital interaction energy component of $-47.8 \mathrm{kcal} / \mathrm{mol}$, whereas the second-largest orbital interaction energy component $\left(\Delta \rho_{\text {orb }}^{2}\right)$ is $-38.9 \mathrm{kcal} / \mathrm{mol}$. These two components are almost complementary in terms of shape: as in $\Delta \rho_{\text {orb }}^{1}$ the origin of the charge concentration is the lone pair of $\pi$ symmetry on the terminal carbon, while in $\Delta \rho_{\text {orb }}^{2}$ the charge flow starts from the carbonyl group of the ketene fragment.
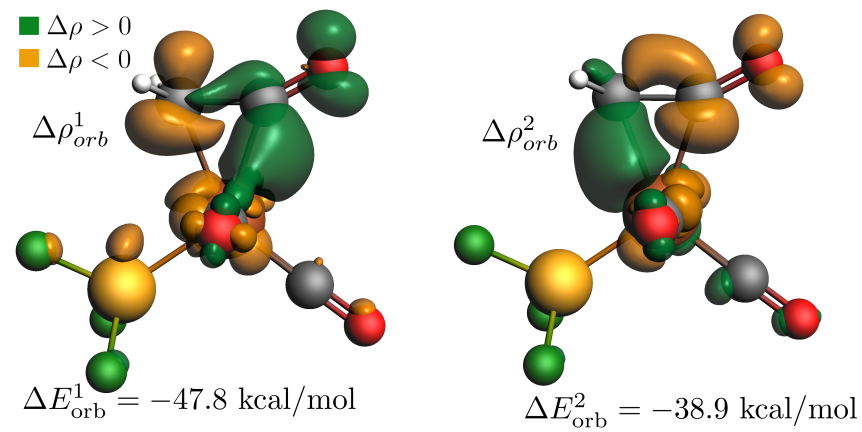

Figure 8. NOCV deformation densities associated with the dominant two interactions of the ketene complex 9F2.

To gain further insight into the coordination properties of ketene bound to the $\mathrm{Fe}(\mathrm{CO})_{3}\left(\mathrm{CF}_{3}\right)$ fragment, NBO calculations were performed with the goal of finding the leading $\pi$-donor and $\pi$-acceptor interactions. Natural localized molecular orbitals (NLMOs) are based on parent NBOs 
extended with delocalization tails, thereby representing electron pairs with an occupation number of 2 [32]. The parent NBO of the NLMO representing the $\pi$-donor pair is the lone pair of the terminal carbon, mainly based on the $p_{z}$ natural atomic orbital (NAO) . To a smaller extent, the $\pi^{*}$ orbitals of the perpendicular CO ligands are involved in the $\pi$-donor interaction. The main source of the back donation interaction is the lone pair of iron, which is an out-of-phase hybrid of the $3 d_{x^{2}-y^{2}}$ and the $3 d_{z^{2}}$ NAOs, interacting with the $\pi_{C O}^{*}$ NBO (Figure 9).

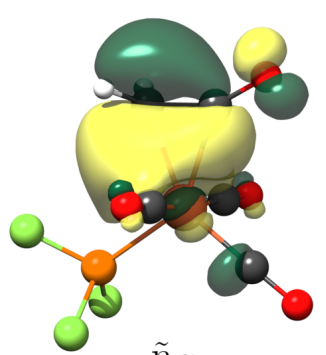

$\tilde{n}_{\mathrm{C}}$
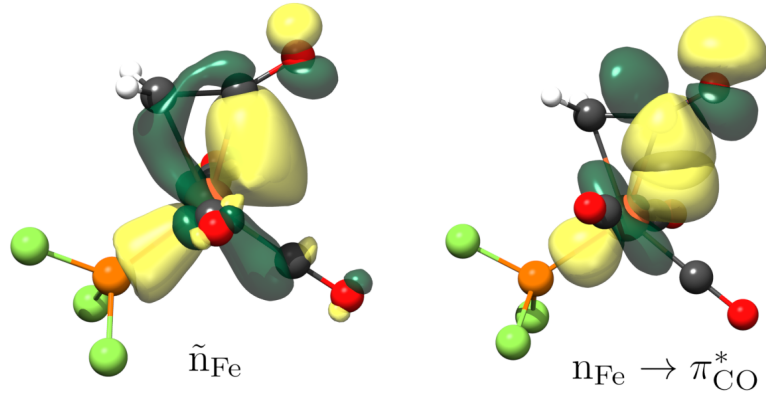

Figure 9. Natural localized molecular orbitals (NLMOs) for the leading donating interaction (left), and for the leading back-donating interaction (middle). On the right side, the dominant interaction of the NBOs for the back-donation is depicted.

\subsection{Overall Reaction Mechanism}

The free energy diagram of the more preferred pathways for the triphenylphosphine and phosphorus trifluoride complexes are shown in Figure 10. The coordination strength of ketene in the saturated complexes 9F1, 9F2, 9P1, and 9P2 are still not enough to establish stable ketene complexes, which could be resting states on the respective potential energy hypersurfaces. Thus, the dissociation of ketene and the coordination of $\mathrm{CO}$ leads to initial complexes $\mathbf{1 F}$ and $\mathbf{1 P}$ with free energy changes of -8.4 and $-16.9 \mathrm{kcal} / \mathrm{mol}$, respectively, closing the catalytic cycle.

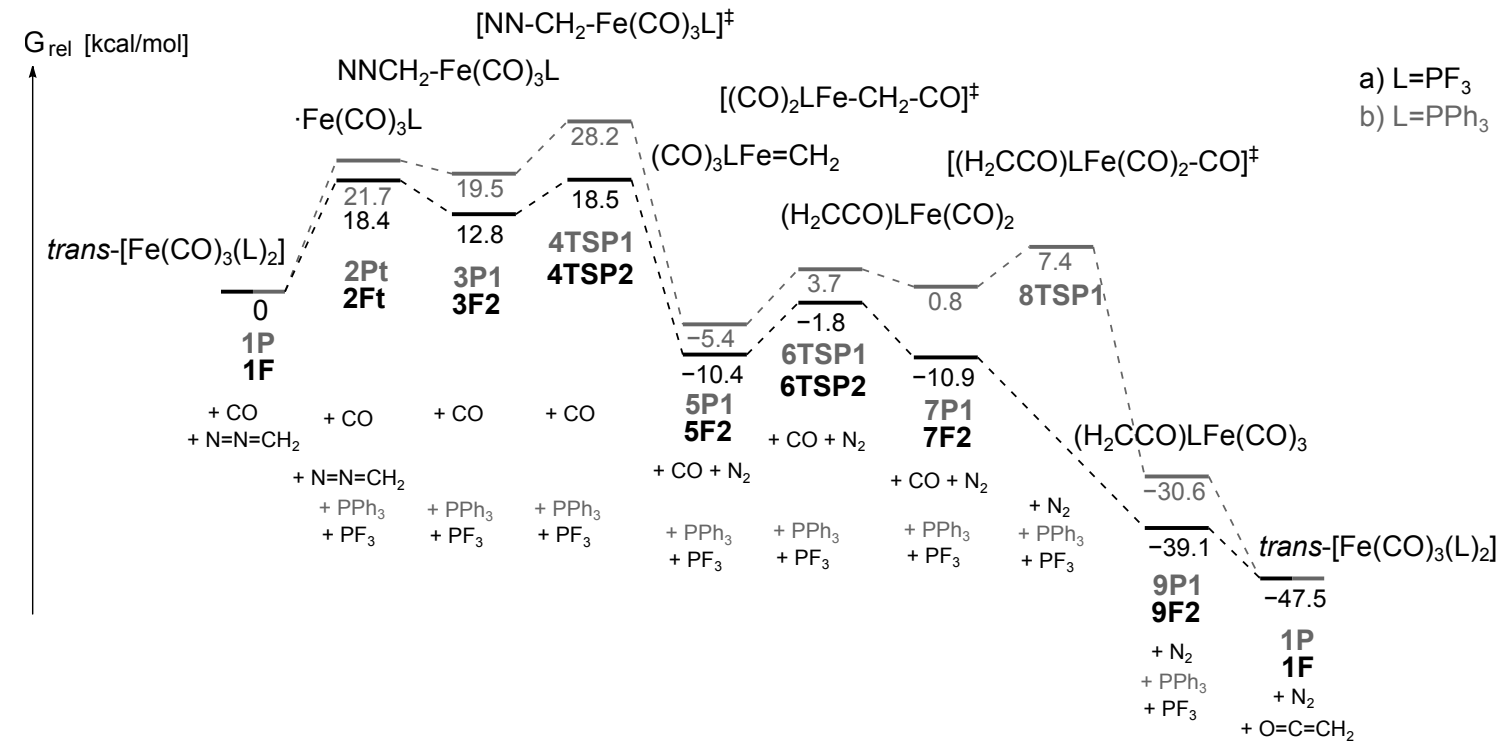

Figure 10. Free energy profile of the diazocarbonylation reaction catalyzed by iron-carbonyl-phosphine complexes. Free energy values are given in $\mathrm{kcal} / \mathrm{mol}$.

The reaction mechanism itself shows no substantial difference as compared to those for cobalt- and nickel-containing systems; the formation of the coordinatively unsaturated active catalyst is followed by the diazo coordination and $\mathrm{N}_{2}$ extrusion, providing the combined rate-limiting step throughout the reaction. The carbene-carbonyl coupling is reasonably fast, resulting in the coordinatively unsaturated 
ketene complexes. The $\mathrm{CO}$ uptake is strongly exergonic in all cases, resulting in the saturated ketene complexes, and the dissociation of the ketene ligand is also exergonic.

\section{Computational Details}

All the structures were optimized without symmetry constraints with tight convergence criteria using the programs ORCA 4.2.1 [33], with the exchange and correlation functionals developed by Grimme [34] containing the D3 empirical dispersion correction with Becke and Johnson damping [35], and denoted as B97D3. For all the atoms the def2-TZVP basis set [36] was employed.

On the equilibrium geometries, the energies have been recomputed with the M06 functional employing the SMD solvation method with dichloromethane as the solvent $\left(\varepsilon_{0}=8.93\right)$. The thermal corrections to the Gibbs free energy were obtained at the B97D3 level.

Natural bond orbital (NBO) analyses have been performed by the GENNBO 7.0 program [37] Quantum theory of atoms in molecules (QTAIM) analyses of the wave function [38] were carried out with the AIMAll software [39]. For both methods, the input files were created with the Gaussian 16, Revision C.01 [40] package. For the EDA-NOCV calculations, the ADF 2019 software was used [41] employing the PBEPBE functional in combination with the triple- $\zeta$ STO basis set for all atoms with one set of polarization functions (denoted as TZP) and a small frozen core.

\section{Conclusions}

The mechanism of iron-catalyzed diazocarbonylation has been investigated by means of density functional calculations at the M06/def-TZVP//B97D3/def2-TZVP level of theory in combination with the SMD solvation method. The results disclosed herein can be summarized as follows.

- In the presence of phosphine, the course of the reaction resembles that obtained for the nickel-carbonyl catalysts; that is, the $\eta^{1}$-diazoalkane complexes lose $\mathrm{N}_{2}$, and the resulting carbenoids undergo carbene-carbonyl coupling affording coordinatively unsaturated ketene complexes.

- The active catalysts for the iron-catalyzed diazocarbonylation are predicted to be the triplet state $\mathrm{Fe}(\mathrm{CO})_{3}(\mathrm{P})$ complexes, which are formed via a spin change from the corresponding singlet state $\mathrm{Fe}(\mathrm{CO})_{3}(\mathrm{P})_{2}$ species. The coordination of the diazoalkane proceeds through another spin change.

- As for the other metals, the rate-limiting step is the combination of catalyst formation, diazo coordination and the exergonic $\mathrm{N}_{2}$ extrusion. The carbene-carbonyl coupling is slightly exergonic for $\mathrm{PF}_{3}$ and endergonic for $\mathrm{PPh}_{3}$. The $\mathrm{CO}$ uptake, leading to the coordinatively saturated ketene complexes, is exergonic, as well as the dissociation of the ketene ligand from the iron center.

- Electron-withdrawing P-donor ligands, such as phosphorus trifluoride, are predicted to increase the reaction rate, in comparison to that obtained with triphenylphosphine.

- Diazomethane can follow $\eta^{1}-\mathrm{C}$ or $\eta^{1}-\mathrm{N}$ coordination; both types of adducts are close to each other in terms of relative free energy.

- According to EDA-NOCV calculations, the charge flow cannot be separated clearly between the ketene and the metal-containing fragment. The more localized NBO approach shows, however, that the main source of the $\pi$-donor interaction is the lone pair of the terminal carbon, mainly based on the $2 p_{z}$ natural atomic orbital, whereas the back-donation is based mainly on the lone pair of iron, which is an out-of-phase hybrid of the $3 d_{x^{2}-y^{2}}$ and the $3 d_{z^{2}}$ natural atomic orbitals, interacting with the $\pi_{C O}^{*}$ orbital of bound ketene.

Thus, according to the calculations, the phosphine-modified iron carbonyl systems are expected to work as catalysts in diazocarbonylation, and possibly in domino reactions based on the catalytic preparation of ketenes. Work is underway in our laboratory to optimize the reaction conditions and to find the most appropriate P-donor ligands for the catalytic transformations. 
Supplementary Materials: The following are available online. Figure S1: Computed structure of the triplet state adduct $\mathrm{Fe}(\mathrm{CO})_{3}\left(\mathrm{PF}_{3}\right)_{2}$; Figure S2: Computed structure of the triplet transition state for the associative pathway between complex $3 \mathrm{~F} 1$ and $\cdot \mathrm{Fe}(\mathrm{CO})_{3}\left(\mathrm{PF}_{3}\right)$ leading to $\mathrm{Fe}(\mathrm{CO})_{3}\left(\mathrm{PF}_{3}\right)\left(\mathrm{CH}_{2}\right)$ and $\mathrm{Fe}(\mathrm{CO})_{3}\left(\mathrm{PF}_{3}\right)\left(\mathrm{N}_{2}\right)$; Table S1: Cartesian coordinates of all computed structures.

Author Contributions: L.K. and T.K. conceived and designed the computational work; T.R.K. performed the calculations; T.K. wrote the paper. All authors have read and agreed to the published version of the manuscript.

Funding: This research received no external funding.

Acknowledgments: This work has been supported by the GINOP-2.3.2-15-2016-00049 grant and European Social Fund Grant no. EFOP-3.6.1.-16-2016-00004 entitled by Comprehensive Development for Implementing Smart Specialization Strategies at the University of Pécs. The authors thank the Supercomputer Center of the National Information Infrastructure Development (NIIF) Program.

Conflicts of Interest: The authors declare no conflict of interest.

\section{References}

1. Tidwell, T.T. Ketenes; John Wiley \& Sons: Hoboken, NJ, USA, 1995.

2. Tidwell, T.T. Ketene chemistry: The second golden age. Acc. Chem. Res. 1990, 23, 273-279. [CrossRef]

3. Tidwell, T.T. The first century of ketenes (1905-2005): The birth of a versatile family of reactive intermediates. Angew. Chem. Int. Ed. 2005, 44, 5778-5785. [CrossRef] [PubMed]

4. Tidwell, T.T. Ketene chemistry after 100 years: Ready for a new century. Eur. J. Org. Chem. 2006, 563-576. [CrossRef]

5. Allen, A.D.; Tidwell, T.T. New Directions in Ketene Chemistry: The Land of Opportunity. Eur. J. Org. Chem. 2012, 2012, 1081-1096. [CrossRef]

6. Tidwell, T.T. Ketenes II, 2nd ed.; John Wiley \& Sons: Hoboken, NJ, USA, 2006.

7. Tidwell, T.T. Hugo (Ugo) Schiff, Schiff Bases, and a Century of $\beta$-Lactam Synthesis. Angew. Chem. Int. Ed. 2008, 47, 1016-1020. [CrossRef]

8. Allen, A.D.; Tidwell, T.T. Ketenes and other cumulenes as reactive intermediates. Chem. Rev. 2013, 113, 7287-7342. [CrossRef]

9. Fördős, E.; Tuba, R.; Párkányi, L.; Kégl, T.; Ungváry, F. Application of the Octacarbonyldicobalt-Catalyzed Carbonylation of Ethyl Diazoacetate for the One-Pot Synthesis of N-tert-Butyl-trans- $\alpha$-ethoxycarbonyl$\beta$-phenyl- $\beta$-lactam. Eur. J. Org. Chem. 2009, 2009, 1994-2002. [CrossRef]

10. Balogh, J.; Kégl, T.; Ungváry, F.; Skoda-Földes, R. $\mathrm{Co}_{2}(\mathrm{CO})_{8}$-induced domino reactions of ethyl diazoacetate, carbon monoxide and ferrocenylimines leading to 2-(1-ferrocenyl-methylidene)-malonic acid derivatives. Tetrahedron Lett. 2009, 50, 4727-4730. [CrossRef]

11. Balogh, J.; Kégl, T.; Párkányi, L.; Kollár, L.; Ungváry, F.; Skoda-Földes, R. Synthesis of (E)-2(1-ferrocenylmethylidene) malonic acid derivatives by a cobalt-catalyzed domino reaction of ethyl diazoacetate, carbon monoxide and ferrocenylimines. J. Organomet. Chem. 2011, 696, 1394-1403. [CrossRef]

12. Rüchardt, C.; Schrauzer, G.N. Über die Carbonylierung von Carbenen und die katalytische Zersetzung von Diazoalkanen mit Nickelcarbonyl. Chem. Ber. 1960, 93, 1840-1848. [CrossRef]

13. Grotjahn, D.B.; Bikzhanova, G.A.; Collins, L.S.; Concolino, T.; Lam, K.C.; Rheingold, A.L. Controlled, reversible conversion of a ketene ligand to carbene and CO ligands on a single metal center. J. Am. Chem. Soc. 2000, 122, 5222-5223. [CrossRef]

14. Grotjahn, D.B.; Collins, L.S.B.; Wolpert, M.; Bikzhanova, G.A.; Lo, H.C.; Combs, D.; Hubbard, J.L. First Direct Structural Comparison of Complexes of the Same Metal Fragment to Ketenes in Both C,C- and C,O-Bonding Modes. J. Am. Chem. Soc. 2001, 123, 8260-8270. [CrossRef] [PubMed]

15. Tuba, R.; Ungváry, F. Octacarbonyl dicobalt-catalyzed selective transformation of ethyl diazoacetate into organic products containing the ethoxycarbonyl carbene building block. J. Mol. Catal. A Chem. 2003, 203, 59-67. [CrossRef]

16. Ungvári, N.; Kégl, T.; Ungváry, F. Octacarbonyl dicobalt-catalyzed selective carbonylation of (trimethylsilyl)diazomethane to obtain (trimethylsilyl)ketene. J. Mol. Catal. A Chem. 2004, 219, 7-11. [CrossRef] 
17. Fördős, E.; Ungvári, N.; Kégl, T.; Ungváry, F. Reactions of ${ }^{13} \mathrm{CO}$ with Ethoxycarbonylcarbene-Bridged Dicobalt Carbonyl Complexes: [ $\mu_{2}$-Ethoxycarbonyl (methylene)- $\mu_{2}$-(carbonyl) bis (tricarbonylcobalt)(Co-Co)] and [Di- $\mu_{2}$-ethoxycarbonyl (methylene) bis (tricarbonylcobalt)(Co-Co)]. Eur. J. Inorg. Chem. 2006, 2006, 1875-1880. [CrossRef]

18. Kégl, T.; Ungváry, F. Internal carbon monoxide exchange and CO dissociation in cobalt carbonyl carbene complexes. A density functional study. J. Organomet. Chem. 2007, 692, 1825-1833. [CrossRef]

19. Kégl, T.; Ungváry, F. The cobalt-catalyzed ketene formation from diazoalkanes. Lett. Org. Chem. 2010, 7, 634-644. [CrossRef]

20. Ungvári, N.; Fördős, E.; Kégl, T.; Ungváry, F. Mechanism of the cobalt-catalyzed carbonylation of ethyl diazoacetate. Inorg. Chim. Acta 2010, 363, 2016-2028. [CrossRef]

21. Ungvári, N.; Fördős, E.; Balogh, J.; Kégl, T.; Párkányi, L.; Ungváry, F. Triphenylphosphane-modified cobalt catalysts for the selective carbonylation of ethyl diazoacetate. Organometallics 2010, 29, 3837-3851. [CrossRef]

22. Zhang, Z.; Liu, Y.; Ling, L.; Li, Y.; Dong, Y.; Gong, M.; Zhao, X.; Zhang, Y.; Wang, J. Pd-catalyzed carbonylation of diazo compounds at atmospheric pressure: A catalytic approach to ketenes. J. Am. Chem. Soc. 2011, 133, 4330-4341. [CrossRef]

23. Barcs, B.; Kollár, L.; Kégl, T. Density Functional Study on the Mechanism of Nickel-Mediated Diazo Carbonylation. Organometallics 2012, 31, 8082-8097. [CrossRef]

24. Harvey, J.N.; Aschi, M. Modelling spin-forbidden reactions: Recombination of carbon monoxide with iron tetracarbonyl. Faraday Discuss. 2003, 124, 129-143. [CrossRef] [PubMed]

25. Mortensen, S.R.; Kepp, K.P. Spin propensities of octahedral complexes from density functional theory. J. Phys. Chem. A 2015, 119, 4041-4050. [CrossRef] [PubMed]

26. Mitoraj, M.P.; Michalak, A.; Ziegler, T. A Combined Charge and Energy Decomposition Scheme for Bond Analysis. J. Chem. Theory Comput. 2009, 5, 962-975. [CrossRef]

27. Michalak, A.; Mitoraj, M.; Ziegler, T. Bond orbitals from chemical valence theory. J. Phys. Chem. A 2008, 112, 1933-1939. [CrossRef]

28. Mitoraj, M.; Michalak, A. Donor-Acceptor Properties of Ligands from the Natural Orbitals for Chemical Valence. Organometallics 2007, 26, 6576-6580. [CrossRef]

29. Mitoraj, M.P.; Michalak, A. $\sigma$-donor and $\pi$-acceptor properties of phosphorus ligands: An insight from the natural orbitals for chemical valence. Inorg. Chem. 2010, 49, 578-582. [CrossRef]

30. Cohen, R.; Rybtchinski, B.; Gandelman, M.; Rozenberg, H.; Martin, J.M.; Milstein, D. Metallacarbenes from diazoalkanes: An experimental and computational study of the reaction mechanism. J. Am. Chem. Soc. 2003, 125, 6532-6546. [CrossRef]

31. Fortman, G.C.; Kégl, T.; Li, Q.S.; Zhang, X.; Schaefer, H.F.; Xie, Y.; King, R.B.; Telser, J.; Hoff, C.D. Spectroscopic Detection and Theoretical Confirmation of the Role of $\mathrm{Cr}_{2}(\mathrm{CO})_{5}\left(\mathrm{C}_{5} \mathrm{R}_{5}\right)_{2}$ and $\cdot \mathrm{Cr}(\mathrm{CO})_{2}$ (ketene) $\left(\mathrm{C}_{5} \mathrm{R}_{5}\right)$ as Intermediates in Carbonylation of $\mathrm{NNCHSiMe}_{3}$ to $\mathrm{OCCHSiMe}_{3}$ by . $\mathrm{Cr}(\mathrm{CO})_{3}\left(\mathrm{C}_{5} \mathrm{R}_{5}\right)\left(\mathrm{R}=\mathrm{H}, \mathrm{CH}_{3}\right)$. J. Am. Chem. Soc. 2007, 129, 14388-14400. [CrossRef]

32. Reed, A.E.; Curtiss, L.A.; Weinhold, F. Intermolecular Interactions from a Natural Bond Orbital, Donor-Acceptor Viewpoint. Chem. Rev. 1988, 88, 899-926. [CrossRef]

33. Neese, F. The ORCA program system. WIREs Comput. Mol, Sci. 2012, 2, 73-78. [CrossRef]

34. Grimme, S. Accurate description of van der Waals complexes by density functional theory including empirical corrections. J. Comput. Chem. 2004, 25, 1463-1473. [CrossRef] [PubMed]

35. Grimme, S.; Ehrlich, S.; Goerigk, L. Effect of the damping function in dispersion corrected density functional theory. J. Comput. Chem. 2011, 32, 1456-1465. [CrossRef] [PubMed]

36. Weigend, F.; Ahlrichs, R. Balanced basis sets of split valence, triple zeta valence and quadruple zeta valence quality for H to Rn: Design and assessment of accuracy. Phys. Chem. Chem. Phys. 2005, 7, 3297-3305. [CrossRef] [PubMed]

37. Glendening, E.D.; Badenhoop, J.K.; Reed, A.E.; Carpenter, J.E.; Bohmann, J.A.; Morales, C.M.; Landis, C.R.; Weinhold, F. NBO 7.0; Theoretical Chemistry Institute, University of Wisconsin: Madison, WI, USA, 2018.

38. Bader, R.F.W. Atoms in Molecules—A Quantum Theory; Oxford University Press: Oxford, UK, 1990.

39. Keith, T.A. AIMAll (Version 19.10.12), TK Gristmill Software, Overland Park KS, USA, 2019. Available online: aim.tkgristmill.com (accessed on 19 October 2019) .

40. Frisch, M.J.; Trucks, G.W.; Schlegel, H.B.; Scuseria, G.E.; Robb, M.A.; Cheeseman, J.R.; Scalmani, G.; Barone, V.; Mennucci, B.; Petersson, G.A.; et al. Gaussian 16 Revision C.01; Gaussian Inc.: Wallingford, CT, USA, 2016. 
41. ADF2019. SCM, Theoretical Chemistry, Vrije Universiteit, Amsterdam, The Netherlands. 2019. Available online: http:/ / www.scm.com (accessed on 25 May 2019).

Sample Availability: Samples of the compounds are not available from the authors.

Publisher's Note: MDPI stays neutral with regard to jurisdictional claims in published maps and institutional affiliations.

(C) 2020 by the authors. Licensee MDPI, Basel, Switzerland. This article is an open access article distributed under the terms and conditions of the Creative Commons Attribution (CC BY) license (http://creativecommons.org/licenses/by/4.0/). 